\title{
Open source approaches to establishing Roseobacter clade bacteria as synthetic biology chassis for biogeoengineering
}

Yanika Borg, Aurelija Marija Grigonyte, Philipp Boeing, Bethan Darren Wolfenden, Patrick Smith, William Beaufoy, Simon Rose, Tonderai Ratisai, Alexey Zaikin, Darren N Nesbeth

Aim. The nascent field of bio-geoengineering stands to benefit from synthetic biologists' efforts to standardise and in so doing democratise biomolecular research methods. Roseobacter clade bacteria comprise $15-20 \%$ of oceanic bacterio-plankton communities, making them a prime candidate for establishment of synthetic biology chassis for biogeoengineering activities such as bioremediation of oceanic waste plastic. Developments such as the increasing affordability of DNA synthesis and laboratory automation continue to foster the establishment of a global 'do-it-yourself' research community alongside the more traditional arenas of academe and industry. As a collaborative group of citizen, student and professional scientists we sought to test the following hypotheses: i) that an incubator capable of cultivating bacterial cells can be constructed entirely from nonlaboratory items, ii) that marine bacteria from the Roseobacter clade can be established as a genetically tractable synthetic biology chassis using plasmids conforming to the BioBrick ${ }^{\mathrm{TM}}$ standard and finally, iii) that identifying and subcloning genes from a Roseobacter clade species can readily by achieved by citizen scientists using open source cloning and bioinformatic tools. Method. We cultivated three Roseobacter species, Roseobacter denitrificans, Oceanobulbus indolifex and Dinoroseobacter shibae. For each species we measured chloramphenicol sensitivity, viability over 11 weeks of glycerolbased cryopreservation and tested the effectiveness of a series of electroporation and heat shock protocols for transformation using a variety of plasmid types. We also attempted construction of an incubator-shaker device using only publicly available components. Finally, a subgroup comprising citizen scientists designed and attempted a procedure for isolating the cold resistance anf1 gene from Oceanobulbus indolifex cells and subcloning it into a BioBrick ${ }^{T M}$ formatted plasmid. Results. All species were stable over 11 weeks of glycerol cryopreservation, sensitive to $17 \mu \mathrm{g} / \mathrm{mL}$ chloramphenicol and resistant to transformation using the conditions and plasmids tested. An incubator-shaker device, 'UCLHack-12' was assembled and used to cultivate sufficient quantity of Oceanobulbus. indolifex cells to enable isolation of the anf1 gene and its subcloning into a plasmid to generate the BioBrick ${ }^{T M} B_{B} a_{-}$K729016. Conclusion. The process of 'de-skilling' biomolecular techniques, particularly for relatively under-investigated organisms, is still 
on-going. However, our successful cell growth and DNA manipulation experiments serve to indicate the types of capabilities that are now available to citizen scientists. Science democratised in this way can make a positive contribution to the debate around the use of bio-geoengineering to address oceanic pollution or climate change. 
1 Open source approaches to establishing Roseobacter clade bacteria as synthetic biology

2 chassis for bio-geoengineering.

3 Yanika Borg*1,2, Aurelija Marija Grigonyte*3, Philipp Boeing ${ }^{4}$, Bethan Wolfenden ${ }^{4}$, Patrick

4 Smith $^{5}$, William Beaufoy ${ }^{5}$, Simon Rose ${ }^{5}$, Tonderai Ratisai ${ }^{5}$, Alexei Zaikin ${ }^{2}$, Darren N.

5 Nesbeth**1.

$6 \quad{ }^{1}$ The Advanced Centre for Biochemical Engineering, Department of Biochemical

7 Engineering, Bernard Katz Building, Gordon Street, University College London, London,

8 WCIE 6BT, UK.

$9{ }^{2}$ Department of Mathematics, University College London, Gower Street, London, WC1E 6BT,

$10 U K$

$11{ }^{3}$ Synthetic Biology Centre for Doctoral Training, University of Warwick, Coventry CV4 7AL,

$12 U K$

13 4Bento Bioworks, UCL Advances, Gordon House, 29 Gordon Square, London, WC1H OPP,

$14 U K$.

$15{ }^{5}$ London BioHackspace, London Biological Laboratories, 447 Hackney Road, London, E2

$169 D Y, U K$.

$17 *$ Contributed equally to this work.

$18 * *$ Corresponding author: The Advanced Centre for Biochemical Engineering, Department of

19 Biochemical Engineering, Bernard Katz Building, Gordon Street, University College London,

20 London, WC1E 6BT, UK.

21 Tel: +44 (0) 207679 9582, Fax: +44 (0) 207209 0703,

22 Email: d.nesbeth@ucl.ac.uk 


\section{Abstract}

24 Aim. The nascent field of bio-geoengineering stands to benefit from synthetic biologists' efforts to standardise and in so doing democratise biomolecular research methods. At times Roseobacter

26 clade bacteria can comprise up to $20 \%$ of a bacterio-plankton community in a given oceanic

27 location, making them a prime candidate for establishment of synthetic biology chassis for bio28 geoengineering activities such as bioremediation of oceanic waste plastic. Developments such as 29 the increasing affordability of DNA synthesis and laboratory automation continue to foster the establishment of a global 'do-it-yourself' research community alongside the more traditional

31 arenas of academe and industry. As a collaborative group of citizen, student and professional scientists we sought to test the following hypotheses: i) that an incubator capable of cultivating bacterial cells can be constructed entirely from non-laboratory items, ii) that marine bacteria

34 from the Roseobacter clade can be established as a genetically tractable synthetic biology chassis using plasmids conforming to the BioBrick ${ }^{\mathrm{TM}}$ standard and finally, iii) that identifying and subcloning genes from a Roseobacter clade species can readily by achieved by citizen scientists using open source cloning and bioinformatic tools. Method. We cultivated three Roseobacter species, Roseobacter denitrificans, Oceanobulbus indolifex and Dinoroseobacter shibae. For each species we measured chloramphenicol sensitivity, viability over 11 weeks of glycerol-based cryopreservation and tested the effectiveness of a series of electroporation and heat shock

41 protocols for transformation using a variety of plasmid types. We also attempted construction of 42 an incubator-shaker device using only publicly available components. Finally, a subgroup comprising citizen scientists designed and attempted a procedure for isolating the cold resistance gene, Antifreeze protein type I (European Bioinformatics code $=$ EDQ05862.1, locus code $=$ 
45 OIHEL45_03590, referred to here as anf1), from Oceanobulbus indolifex cells and sub-cloning it 46 into a BioBrick ${ }^{\mathrm{TM}}$ formatted plasmid.

47 Results. All species were stable over 11 weeks of glycerol cryopreservation, sensitive to $17 \mu \mathrm{g} /$ $48 \mathrm{~mL}$ chloramphenicol and resistant to transformation using the conditions and plasmids tested. An 49 incubator-shaker device, 'UCLHack-12' was assembled and used to cultivate sufficient quantity 50 of Oceanobulbus. indolifex cells to enable isolation of the anfl gene and its subcloning into a 51 plasmid to generate the BioBrick ${ }^{\mathrm{TM}}$ BBa_K729016.

52 Conclusion. The process of 'de-skilling' biomolecular techniques, particularly for relatively 53 under-investigated organisms, is still on-going. However, our successful cell growth and DNA 54 manipulation experiments serve to indicate the types of capabilities that are now available to 55 citizen scientists. Science democratised in this way can make a positive contribution to the 56 debate around the use of bio-geoengineering to address oceanic pollution or climate change. 


\section{Introduction}

59 The last decade has seen increased discussion as to whether global phenomena that result from

60 human activity, such as climate change (Rayner et al., 2013) and oceanic pollution (Hale and

61 Dilling, 2011), can and should be met with geoengineering (Stilgoe, 2015, IMBECS 2014) and

62 bio-geoengineering (Singarayer and Davis-Barnard, 2012) solutions. Synthetic biology has

63 begun to feature in this field due to developments such as the proposed used of gene drives (Jin

64 et al., 2013) to control insect populations in the wild. Conventional bio-geoengineering proposals

65 involve the re-seeding of naturally occurring organisms, such as certain barley varieties, in non-

66 native geographical locations to increase global solar reflectivity (Ridgwell et al., 2009).

67 A major challenge for synthetic biology approaches to bio-geoengineering is the establishment of 68 organisms, or 'chassis', that are viable in natural habitats. Natural environments tend to be 69 physically and chemically harsh and possess only scarce nutrient sources. This contrasts with the 70 laboratory environment, which is constantly monitored, maintained and optimised to achieve 71 maximal growth of laboratory-adapted organisms such as E. coli K-12 (Bachmann, 1972), $P$. 72 pastoris GS115 (De Schutter et al., 2009) and Chinese hamster ovary cells (Xu et al., 2011).

73 In this study we seek to exploit properties of a clade of marine bacteria, Roseobacter (Brinkhoff

74 et al., 2008), as a chassis for marine applications of synthetic biology and a source of genetic

75 material that could be used to confer upon more conventional chassis, such as E. coli, the ability

76 to grow in a marine environment. We anticipate that establishing standard tools to engineer

77 marine bacteria could underpin the future deployment of a designed organism in the world's

78 oceans capable of sensing and degrading the waste plastics observed to accumulate in oceanic

79 gyres (Eriksen et al., 2014). We also anticipate that any such bio-geoengineering steps would

80 only be taken with broad societal consent, of the type described by Stilgoe (2015) and others 
81 (Rayner et al., 2013). As an interdisciplinary team of professional scientists, student scientists

82 and citizen scientists, we embarked on this study as a means of exploring the logistical,

83 scientific, didactic and ethical challenges and opportunities presented by scientific research

84 practiced by members of the public in a non-conventional research setting.

85 Roseobacter is one of the nine major clades of marine bacteria (Buchan et al., 2005) that provide

86 the vast bacterial diversity present in the world's oceans. Roseobacter can represent up to a fifth

87 of the total species present in bacterio-plankton communities at certain oceanic depths and

88 periods within a given year (González et al., 1999). Due to their extreme versatility, Roseobacter

89 clade bacteria can survive in aerobic and anaerobic environments, interact with eukaryotic cells

90 via symbiosis (Buchan et al., 2005), utilise quorum-sensing mechanisms (Zan et al., 2014),

91 facilitate the oxidation of carbon monoxide to carbon dioxide (Brinkhoff et al., 2008) and also

92 produce dimethylsulfide, a key component of the global sulphur cycle (Hahnke et al., 2013).

93 The genomes of over 40 Roseobacter strains have been sequenced (Petersen et al., 2013) but

94 only one group has demonstrated transformation of Roseobacter species with recombinant

95 plasmids (Piekarski et al., 2009). Establishing a Roseobacter strain that is sufficiently genetically

96 tractable to be used in 'de-skilled', robust and reliable modification protocols could enable the

97 application of designed organisms to address pressing challenges such as climate change

98 (Ridgwell et al., 2009) and plastic pollution (Dash et al., 2012). 50-80\% of sea-debris on

99 beaches, the seabed and floating in the ocean has been estimated to consist of micro-plastics

100 (Barnes et al., 2009; Hidalgo-Ruz and Thiel, 2013). Marine bacteria controlled by synthetic gene

101 networks or genomes have the potential to be used as plastic remediation systems that utilise

102 laccases, enzymes capable of degrading polyethylene into non-hazardous polymers (Santo et al., 103 2012). 
104 A significant step in establishing a bacterial species as a synthetic biology chassis is to establish

105 whether plasmids compliant with the BioBrick ${ }^{\mathrm{TM}}$ format can be used for transformation. The

106 BioBrick $^{\mathrm{TM}}$ plasmid format is shared by all parts (plasmids) available from the open Registry of

107 Standard Biological Parts, which is maintained by the International Genetically Engineered

108 Machines (iGEM) Foundation (Boston, USA). This registry is a large plasmid library maintained

109 by the staff of the iGEM annual synthetic biology competition (Müller and Arndt, 2012) and

110 curated in part by users. Every plasmid in the BioBrick ${ }^{\mathrm{TM}}$ format is compatible with every other

111 BioBrick $^{\mathrm{TM}}$ and so demonstrating the use of one BioBrick ${ }^{\mathrm{TM}}$ plasmid in a Roseobacter species

112 immediately enables the use of several thousand compatible plasmid-based tools to build

113 synthetic genes and gene networks. A given DNA sequence can be classified as a BioBrick ${ }^{\mathrm{TM}}$

114 part if it is flanked upstream by a defined sequence motif which encodes, in order, unique EcoRI,

115 NotI and XbaI restriction sites and flanked downstream by a sequence encoding, in order, unique

116 SpeI, NotI and PstI sites (Canton et al., 2008; Shetty et al., 2011).

117 The BioBrick ${ }^{\mathrm{TM}}$ format enables recursive rounds of DNA ligation in which the enzymes and

118 procedures used do not change, regardless of the identity of the underlying fragments being

119 assembled. This approach enables an interchangeable 'plug-and-play' strategy for mixing and

120 matching genetic components within a gene or genes within a pathway. This typically results in a

121 more predictable, economically viable, and time efficient practice than conventional ad hoc

122 recombinant DNA strategies (Tabor, 2012). In this study we were keen to establish if a simple

123 and affordable plasmid transformation procedure could be established in the Roseobacter strains,

124 Roseobacter denitrificans ( $R$. denitrificans), Oceanobulbus indolifex $(O$. indolifex) and

125 Dinoroseobacter shibae (D. shibae). Tolerance to cold is also a potentially useful phenotype to

126 port from Roseobacter to E. coli. Toward this end we also attempted to isolate the gene 
127 OIHEL45_03590, encoding Antifreeze protein type I (referred to here as anfl) from O. indolifex,

128 and subclone it into a BioBrick ${ }^{\mathrm{TM}}$ plasmid.

129 In addition to strea mLining and enhancing recombinant DNA procedures in conventional

130 research settings, the BioBrick ${ }^{\mathrm{TM}}$ standard for plasmid design and assembly can also help

131 provide the reproducibility and robustness that enables a methodology to be accessible to

132 members of the public participating in citizen science projects (Wolyniak et al., 2010). Citizen

133 science has led to the public's involvement in a variety of ecology, conservation (Hochachka et

134 al., 2012), biology (Jordan et al., 2011) and genetics (Kawrykow et al., 2012) projects. Known

135 alternatively as 'biohackers', 'citizen scientists', 'garage scientists' and 'DIY biologists'

136 (Ledford, 2010), growing numbers of people are now taking advantage of open source software

137 and hardware. Commonly used open source devices used for 'biohacking' include Arduino

138 prototyping platforms, 3D-printers, spectrophotometers (iGEM 2015), thermal cyclers (Open

139 PCR) for end-point polymerase chain reactions (epPCR) and thermal cyclers with live

140 fluorescence detection (Chai), for quantitative PCR (qPCR). The fact that these tools are open

141 source means that well-equipped laboratories can now be found outside of both academia and

142 industry, in community-based spaces (Alper, 2009; Pearce, 2012).

143 Alternative funding models are increasingly being used to support the running of projects and

144 community laboratories through 'crowdfunding' via online companies that act as intermediaries

145 to enable private individuals to invest in projects or propose ventures (Belleflamme et al. 2014).

146 Active DIYbio projects now range from genetic disease testing to designing water-quality

147 monitoring devices (Alper, 2009; Jorgensen and Grushkin, 2011) and the number and variety of

148 projects carried out by DIYbio groups continues to increase (Freitag and Pfeffer, 2013). 
149 A major goal of this study was to establish collaboration between undergraduate students from

150 University College London (UCL) and members of the public engaged in research at the London

151 BioHackspace Ltd (LBHS). The purpose of the collaboration was to foster skills exchange

152 between UCL and LBHS and also to provide LBHS researchers access to facilities at UCL with

153 the required legal permissions to perform DNA recombination, an activity which was not

154 possible at the LBHS during the period of the project. To achieve these aims UCL and LBHS

155 collaborated to attempt construction of a shaker-incubator device for cultivation of Roseobacter

156 using only publically available components. LBHS members designed a strategy for isolation

157 and subcloning the anfl gene from $O$. indolifex into a BioBrick ${ }^{\mathrm{TM}}$ plasmid backbone. UCL

158 students and LBHS members also attempted to transform $R$. denitrificans, $O$. indolifex and $D$.

159 shibae and characterise these strains with respect to cryopreservation and resistance to an

160 antibiotic commonly used to select for retention of recombinant plasmids. 


\section{Materials and Methods}

163 Unless otherwise stated, all growth media and solutions were sterilised by filtration or

164 autoclaving. All reagents used to isolate or manipulate DNA were certified as molecular biology

165 grade by the supplier.

\section{Safety Considerations}

167 Standard operating procedures and risk assessments were developed prior to the performance of 168 all procedures. The Roseobacter strains investigated require the lowest level of containment,

169 Level 1, as defined by the Advisory Committee on Dangerous Pathogens (ACDP), part of the

170 United Kingdom (UK) Health and Safety Executive (HSE). The template DNA extraction

171 procedure below is a modification of the commonplace method described by Sambrook and

172 Russell 2001 but revised to omit phenol:chloroform due to the absence of organic chemical

173 storage or manipulation facilities at the London BioHackspace at the time of this work. *The

174 efficiency of this modified procedure for extraction of genomic DNA is doubtful and the

175 procedure is reported here in principle as an illustration of the constraints that must sometimes be

176 negotiated to prioritise safety when working in community laboratories.

177 All authors of this work were aware of the illegality of unauthorised environmental release of

178 genetic modified organisms in the UK and regarded the terms of their status either as members of

179 the London BioHackspace or as UCL staff or students as a de facto formal commitment to ensure

180 no such release was attempted. It is also important to consider that a significant body of research

181 is still required to determine if a genetically modified marine bacterium could establish itself and

182 persist in natural environments. The modes of modification considered in this work would

183 inevitably exert a metabolic burden on host cells, reducing their fitness for natural habitats

184 compared to their wild type competitors. 
Bacterial strains and plasmids

187 Three Roseobacter strains were obtained from NCIMB Ltd (Aberdeen, Scotland): $R$. 188 denitrificans OCh114 (Shiba, 1991), O. indolifex HEL-45 (Wagner-Döbler et al., 2004) and D. 189 shibae DFL 12 (Biebl et al. 2005). The E. coli strain W3110 (Bachmann, 1972) was sourced 190 from historic stocks available at UCL.

191 BioBrick ${ }^{\mathrm{TM}}$ formatted plasmids, pSB3C5 (EU496103) and pSB1C3 (AF532313), were supplied 192 by the Registry of Standard Biological Parts (Massachusetts, USA). Plasmids pHD1313 (Alibu 193 et. al, 2004), pRPGFPSIR2rp3 (Borg 2015), pUBeK (Borg 2015) and pAO815 (Invitrogen, 194 California, USA) were also used.

\section{Recombinant DNA procedures}

196 Plasmids were purified from cells using standard commercial 'Mini Prep' kits such as the 197 KeyPrep Spin Plasmid DNA Mini Kit Pk100 (Anachem Ltd., Luton, U.K). Standard molecular 198 biology techniques were used for restriction digests of plasmids and preparative polymerase 199 chain reactions (PCRs). Preparative PCR was performed at LBHS using a Perkin Elmer 200 (Beaconsfield, UK) Thermal Cycler 480 device. The forward primer used for amplification of 201 anfl had the following sequence, with the single-underlined text indicating the Eco RI site, the 202 bold text indicating the Not I site, the double-underlined text indicating the Xba I site and the 203 text underlined with lower case characters indicating the bases complimentary with the anf1 204 ORF:

205 GTTTCTTCGAATTCGCGGCCGCTTCTAGAGGCAAGGGAatgcaagacagc. The reverse 206 primer used for amplification of anfl had the following sequence, with the single-underlined text 207 indicating the Pst I site, the bold text indicating the Not I site, the double-underlined text 
208 indicating the Spe I site and lower case characters again indicating bases complimentary with the

209 anf1 ORF: GTTTCTTCCTGCAGCGGCCGCTACTAGTAGCCTctacttcatcagccgtttg. These

210 sequences include restriction sites in non-coding regions to ensure the amplified anfl gene

211 fragment is compatible with the BioBrick ${ }^{\mathrm{TM}}$ standard. Linearised pSB1C3 plasmid as template

212 was PCR-amplified using the primer, 'SB-prep-3P-1': gccgetgcagtccggcaaaaaa, which anneals at

213 the pSB1C3 PstI site (in bold) and the primer, 'SB-prep-2Ea': atgaattccagaaatcatccttagcg, which

214 anneals at the pSB1C3 EcoRI site (in bold). The amplified pSB1C3 fragment and anf1 amplicons

215 were cut with EcoRI and PstI and ligated. All primers were supplied by Eurofins MWG Operon

216 (Ebersberg, Germany).

217 Preparation of material containing sufficient template DNA for preparative PCR*

218 Due to the lack of equipment for safe handling of phenol:chloroform mixtures at LBHS, the

219 following procedure was followed in the hope of deriving sufficient template genomic DNA

220 from $O$. indolifex culture. 1.5 volumes of $100 \%$ ethanol and 0.1 volumes of $3 \mathrm{M}$ sodium acetate

221 were added to $400 \mu \mathrm{L}$ of $O$. indolifex culture followed by mixing with a vortex for 5 seconds.

222 This material was then placed in a $-20^{\circ} \mathrm{C}$ freezer overnight then centrifuged at $12000 \mathrm{RPM}$ for 20

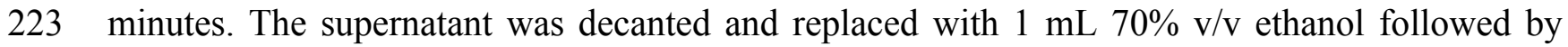

224 centrifugation at 12000 RPM for 10 minutes. The supernatant was decanted and the pellet air-

225 dried and suspended in $30 \mu \mathrm{L}$ water before use as PCR template. The mass of genome DNA that

226 may have been extracted was not measured. An aliquot of this material was used as template in a

227 PCR reaction with primers specific for the $O$. indolifex anfl gene. Successful amplification of a

228 DNA fragment of expected size indicated that some template $O$. indolifex gDNA template was

229 present. However, this may have been due to the persistence of intact cells that were disrupted 
230 subsequently by the $95^{\circ} \mathrm{C}$ denaturation step of PCR. Until further work is carried out, we do not

231 currently propose this preparation method to others as an efficient step for gDNA extraction.

\section{Cell cultivation}

233 Unless otherwise stated all cell cultivation was performed using static and shaking incubators in

234 the UCL Department of Biochemical Engineering, such as the Memmert High Precision

235 Incubator (Memmert GmbH, Schwabach, Germany) and the Kuhner ISF-1-V Climo-Shaker

236 Incubator (Adolf Kuhner AG, Basel, Switzerland) respectively.

237 Components used in construction of the 'UCLHack12' shaker-incubator device

238 The UCLHack12 Public shaker-incubator device (Figure 5) was constructed at LBHS using the

239 following components: an Arduino Esplora micro computer (Dangi internet Electronics S.L.,

240 Almunecar, Spain), a Worldwide Travel Multi-Voltage Power Supply (Maplin Electronics Ltd.,

241 Rotherham, U.K.), an electronic motor (Maplin Electronics Ltd., Rotherham, U.K.), a 9 V PP9

242 battery (Maplin Electronics Ltd., Rotherham, U.K), two 210x148mm cardboard sheets (Ryman

243 Ltd., Cheshire, U.K.), four 8.4 x 44.5mm springs (Maplin Electronics Ltd., Rotherham, U.K.),

244 two pencils (Ryman Ltd., Cheshire, U.K), two L/C 10/0.1mm cable wires (Maplin Electronics

245 Ltd., Rotherham, U.K), 1mm diameter copper metal wire (Minsets Ltd., Herts, U.K.) and a 42L

246 Cool Box (Argos Direct, Stafford, U.K.) to act as an outer chassis and containment barrier.

247 Cryopreservation of cells using glycerol

248 For all three Roseobacter strains a commercial Marine Broth (MB) 2216 was used for cultivation

249 in liquid culture and a commercial MB agar (both Becton-Dickinson, Le Pont de Claix, France)

250 used for growth on plates. Typically, colonies from MB agar plates or $6 \mu \mathrm{L}$ of growth culture

251 were used to inoculate $6 \mathrm{~mL} \mathrm{MB}$ in a $50 \mathrm{~mL}$ Falcon tube. Inoculants were then incubated for 12-

25216 hours with $200 \mathrm{RPM}$ shaking at $37^{\circ} \mathrm{C}$ until typically $\mathrm{OD}_{600}=1-2$ was achieved. After this 1.6 
$253 \mathrm{~mL}$ sterile $80 \% \mathrm{v} / \mathrm{v}$ glycerol was added, and mixed by pipetting up and down. The resultant $17 \%$

$254 \mathrm{v} / \mathrm{v}$ glycerol solution was then divided into $380 \mu \mathrm{L}$ aliquots and stored separately in labelled

255 tubes at $-80^{\circ} \mathrm{C}$. The above procedure was also used for preparation of $E$. coli glycerol stocks

256 using Luria-Bertani (LB) liquid medium and agar plates (Sigma-Aldrich, Munich, Germany).

\section{Antibiotic sensitivity}

258 For each strain, $100 \mu \mathrm{L}$ of cells from a glycerol stock were used to inoculate $100 \mathrm{~mL}$ of MB (LB

259 for E. coli) in a $0.5 \mathrm{~L}$ conical flask which was then incubated at $37^{\circ} \mathrm{C}$ for $12-16$ hours with 200

260 RPM shaking until $\mathrm{OD}_{600} \approx 4$. Four $20 \mathrm{~mL}$ aliquots were taken and to each was added $20 \mathrm{~mL}$

261 MB containing twice the intended final chloramphenicol concentration indicated in Figure 3. The

$26240 \mathrm{~mL}$ culture was mixed by brief, gentle swirling and then split into 16 aliquots of $2 \mathrm{~mL}$, each

263 in $15 \mathrm{~mL}$ Falcon tubes. All tubes were incubated at $37^{\circ} \mathrm{C}$ with shaking at $200 \mathrm{RPM}$ and two 2

$264 \mathrm{~mL}$ cultures removed at the indicated time points for $\mathrm{OD}_{600}$ measurement followed by disposal.

265 For ampicillin sensitivity $100 \mu \mathrm{g} / \mathrm{mL}$ was used as previous work by Piekarski et al (2009)

266 suggested this as a minimum inhibitory ampicillin concentration for use with Roseobacter clade

267 bacteria.

268 Preparation of Roseobacter and E. coli cells competent for plasmid uptake by heat shock

269 Roseobacter strain cells were streaked from a glycerol stock onto a non-selective MB Agar plate

270 and grown for $12-16$ hours at $37^{\circ} \mathrm{C}$. A single colony picked from the plate was used to inoculate

$2715 \mathrm{~mL}$ of $\mathrm{MB}$ in a $50 \mathrm{~mL}$ Falcon tube before $12-16$ hours incubation at $37^{\circ} \mathrm{C}$ with $200 \mathrm{RPM}$

272 shaking until $\mathrm{OD}_{600}=1-2.1 \mathrm{~mL}$ of this culture was used to inoculate $100 \mathrm{~mL} \mathrm{MB}$, in a $0.5 \mathrm{~L}$

273 conical flask, which was further incubated under the same conditions until an $\mathrm{OD}_{600}$ of 0.3 was

274 reached. The culture was transferred to two pre-chilled, sterile $50 \mathrm{~mL}$ tubes and incubated on ice

275 for 10 minutes. A five minute 4,000 RPM centrifugation at $4^{\circ} \mathrm{C}$ was used to pellet cells. The 
276 supernatant was then removed and the pellet resuspended in a $10 \mathrm{~mL}$ ice-cold solution of $0.1 \mathrm{M}$

$277 \mathrm{CaCl}_{2}$ and $15 \% \mathrm{v} / \mathrm{v}$ glycerol and incubated on ice for 30 minutes. This centrifugation step was

278 repeated and the final cell pellet resuspended in $1 \mathrm{~mL}$ ice-cold $0.1 \mathrm{M} \mathrm{CaCl} / 15 \% \mathrm{v} / \mathrm{v}$ glycerol

279 solution, then divided into $100 \mu \mathrm{L}$ aliquots in pre-chilled Eppendorf tubes and stored at $-80^{\circ} \mathrm{C}$.

280 The above procedure was also used for the preparation of competent $E$. coli cells, replacing MB

281 with LB in all steps.

282 Plasmid transformation by heat shock

283 Aliquots of cells putatively competent for transformation by heat shock were removed from 284 storage at $-80^{\circ} \mathrm{C}$ and placed on ice. A maximum volume of $5 \mu \mathrm{L}$ of plasmid solution was 285 pippetted onto still-frozen competent cells before incubation of 45 minutes on ice. After this 286 tubes containing now-thawed cells and plasmid were placed in a $42^{\circ} \mathrm{C}$ water bath for 10 minutes 287 to cause heat-shock then transferred to ice for two minutes before addition of $1.3 \mathrm{~mL}$ of $\mathrm{MB}$. The 288 solution was transferred to a $15 \mathrm{~mL}$ Falcon tube and incubated at $37^{\circ} \mathrm{C}$ with $200 \mathrm{RPM}$ shaking 289 for an hour. This material was transferred to a $1.5 \mathrm{~mL}$ Eppendorf tube and a 14,000 RPM 290 centrifugation for two minutes used to pellet cells. After removal of the supernatant, the cell 291 pellet was resuspended in $100 \mu \mathrm{L}$ MB then spread onto selective MB Agar plates. Resultant 292 colonies were assessed after $12-16$ hours static incubation at $37^{\circ} \mathrm{C}$ and again at 24 and 48 hour 293 time-points. This procedure was also performed using E. coli cells by replacing MB with LB in 294 all steps.

\section{Preparation of Roseobacter cells competent for plasmid uptake by electroporation}

296 Method A. A modified version of the method reported by Piekarski et al. (2009) was used. $50 \mu \mathrm{L}$ 297 of Roseobacter strain glycerol stock was used to inoculate $50 \mathrm{~mL} \mathrm{MB}$ in a conical flask. This 298 inoculum was then incubated at $37^{\circ} \mathrm{C}$ with 200 RPM shaking for 12-16 hours to an OD $_{600}$ of 1-2. 
299 After this a 15 minute, $4000 \mathrm{RPM}$ centrifugation at $4^{\circ} \mathrm{C}$ was used to pellet cells. The supernatant

300 was removed and the cell pellet was resuspended in $10 \mathrm{~mL}$ pre-chilled $10 \% \mathrm{v} / \mathrm{v}$ glycerol. A

301 further four rounds of the same centrifugation, supernatant removal and pellet resuspension

302 prodecure were then performed. The final pellet was resuspended in $1 \mathrm{~mL} 10 \% \mathrm{v} / \mathrm{v}$ glycerol and

303 divided into $50 \mu \mathrm{L}$ aliquots in pre-chilled $1.5 \mathrm{~mL}$ Eppendorf tubes for immediate use.

304 Method B. Cells were prepared as in Method A except all cultivation steps were performed at $30530^{\circ} \mathrm{C}$ and cells were pelleted after having grown to $\mathrm{OD}_{578}$ of 0.5 .

306 Method C. The method reported by Sambrook and Russell (2001) was used. $10 \mu \mathrm{L}$ of 307 Roseobacter strain glycerol stock was used to inoculate $10 \mathrm{~mL}$ MB in a $15 \mathrm{~mL}$ Falcon tube. This 308 inoculum was then incubated at $37^{\circ} \mathrm{C}$ with $200 \mathrm{RPM}$ shaking for $12-16$ hours to an $\mathrm{OD}_{600}$ of 0.5 -

309 1.0. $4 \mathrm{~mL}$ of this material was used to inoculate $400 \mathrm{~mL} \mathrm{MB}$ in a $2 \mathrm{~L}$ conical flask which was

310 incubated as above until an $\mathrm{OD}_{600}$ of $0.5-0.6$ was reached.

311 The conical flask was then chilled on ice for 30 minutes and the $400 \mathrm{~mL}$ of inoculum transferred 312 to a pre-chilled $0.5 \mathrm{~L}$ centrifuge bottle and centrifuged at $4^{\circ} \mathrm{C}$ for 15 minutes at $6,000 \mathrm{RPM}$. The

313 supernatant was removed by aspiration and $400 \mathrm{~mL}$ of ice-cold sterile distilled $\mathrm{H}_{2} \mathrm{O}$ was used to

314 resuspend the cell pellet. This centrifugation, supernatant removal and pellet resuspension

315 procedure was repeated twice before the pellet was finally resuspended in $50 \mathrm{~mL}$ ice-cold $10 \%$

$316 \mathrm{v} / \mathrm{v}$ glycerol solution. This was then transferred to a pre-chilled $50 \mathrm{~mL}$ centrifuge tube and 317 centrifuged at $4^{\circ} \mathrm{C}$ for 15 minutes at $6,000 \mathrm{RPM}$. The supernatant was removed using a pipette 318 and the pellet resuspended in $2 \mathrm{~mL}$ of ice-cold $10 \% \mathrm{v} / \mathrm{v}$ glycerol. This was then divided into 50

$319 \mu \mathrm{L}$ aliquots in pre-chilled $750 \mu \mathrm{L}$ PCR tubes, which were kept on ice and used immediately. This

320 process was also used for $E$. coli cells by substituting MB with LB.

321 Plasmid transformation by electroporation 
322 A maximum volume of $5 \mu \mathrm{L}$ of plasmid solution was added to $50 \mu \mathrm{L}$ putatively competent cells

323 in a pre-chilled $0.2 \mathrm{~cm}$ pulser cuvette (Bio-Rad, California, USA). The mixture was then pulsed

324 in a Gene Pulse Xcell ${ }^{\mathrm{TM}}$ System (Bio-Rad, California, USA) typically using a field strength of

$3250.5-3.0 \mathrm{kV}$, capacitance of $25 \mu \mathrm{F}$ and resistance of $200 \Omega$. Alternative settings are also discussed in

326 the Results section. After electroporation $1 \mathrm{~mL}$ chilled MB was added immediately to the

327 cuvette. For electrocompetent cells generated using Methods A and C, the entire cuvette contents

328 was decanted to a $15 \mathrm{~mL}$ Falcon and incubated at $37^{\circ} \mathrm{C}$ for $12-16$ hours with shaking at 250

329 RPM. For electrocompetent cells generated using Method B, $1 \mathrm{~mL} \mathrm{1.7 \%} \mathrm{w/v} \mathrm{sea} \mathrm{salts} \mathrm{(S9883}$

330 Sigma-Aldrich, Munich, Germany) was added to the cuvette, decanted and split into two $0.5 \mathrm{~mL}$

331 aliquots, each on a $15 \mathrm{~mL}$ Falcon. $0.5 \mathrm{~mL}$ of water was added to one of these aliquot to give a

$332 \quad 0.85 \%$ sea salts solution.

333 For both $\mathrm{MB}$ and sea salt solutions, a $100 \mu \mathrm{L}$ aliquot was spread onto an $\mathrm{MB}$ agar plate

334 containing $17 \mu \mathrm{g} / \mathrm{mL}$ chloramphenicol and incubated at $37^{\circ} \mathrm{C}$ for $12-16$ hours with shaking at

335250 RPM. Colonies were counted the next day and the presence or absence of plasmid

336 confirmed by mini prep, agarose gel analysis and spectrophotometry.

337

338

339

340 The practice of synthetic biology is at its most 'open source', we suggest, when performed by

341 people who are not molecular life science 'experts', such as graduate or postgraduate students of

342 the field, or life science professionals in academe or industry. Toward this end it is advantageous

343 that this project was planned and conceived by four members of the public and three

344 undergraduate (UG) students, as summarised in Figure 1. We define 'member of the public'

345 (MOP) in this instance as somebody who does not have a life science degree and is not studying 
346 for a life science degree. Of the three UG students, two were studying life science degrees and

347 one a degree in computer ccience. The MOPs and UG students met during the summer of 2012.

348 The impetus behind their meeting was the 2012 International Genetically Engineered Machines

349 competition.

350 The UG students received introductory training from postgraduate students at University College

351 London in standard molecular biology technques sufficient to perform BioBrick ${ }^{\mathrm{TM}}$ assembly.

352 The UG students then shared their knowledge with MOPs who had previously been trained using

353 Internet sources and fellow LBHS members from various backgrounds. Together the UG

354 students and MOPs defined this project and led the design of the experiments. One doctoral

355 student assisted closely in this study, Yanika Borg (YB), whose first degree is in mathematics

356 and statistics and who had less than one year of molecular biology experience during this work.

357 YB proviced assistance on the work reported in Figures 2-4, with purely UG students and MOPs

358 involved in the work reported in Figures 5 and 6. With respect to experimentation, UCL faculty

359 member, Darren N. Nesbeth provided only safety supervision and logistical support - but did not

360 conceive the study, choose the topic or design the experiments. Darren N. Nesbeth and fellow

361 UCL faculty member Alexey Zaikin also provided advice on the drafting of the manuscript.

\section{Robustness of Roseobacter strains to glycerol cryopreservation}

363 At the outset of this study we were aware that a number of organisations maintain commercial

364 culture collections, such as NCIMB Ltd (Aberdeen, Scotland) and professional research

365 laboratories, and routinely cryopreserve Roseobacter and E. coli strains. We first aimed to

366 establish whether standard procedures could also achieve reliable preservation of Roseobacter

367 strains $O$. indolifex and $R$. denitrificans when performed by students and members of the public,

368 who are relatively inexperienced with respect to microbiological techniques, and in a community 
369 laboratory setting. Citizen scientists at LBHS typically perform experiments at evenings and

370 weekends on 1-2 occasions per week to fit around employment or other interests. When time and

371 equipment are scarce, separate incubators, or incubator rotas, enabling a choice of cultivation at

$37225^{\circ} \mathrm{C}, 30^{\circ} \mathrm{C}$ or $37^{\circ} \mathrm{C}$ are somewhat of a rarity. The majority of experiments conducted at LBHS

373 are with E. coli cultivated at $37^{\circ} \mathrm{C}$. Because of this we attempted to cultivate Roseobacter cells at

$37437^{\circ} \mathrm{C}$, as successful growth at this temperature would afford maximum flexibility to researchers

375 investigating Roseobacter at LBHS. All four Roseobacter strains in this study grew successfully

376 at $37^{\circ} \mathrm{C}$ in $\mathrm{MB}$ (Figures 2 and 3).

377 We measured the ability of $O$. indolifex and $R$. denitrificans cultures to survive cryopreservation

378 by measuring how many colony forming units (CFU) / $\mathrm{mL}$ remained within glycerol stock

379 solutions each week over 11 weeks (Figure 2, diamond data points). Initial $6 \mathrm{~mL}$ cultures of $O$.

380 indolifex and $R$. denitrificans were cultivated as detailed in Materials and Methods. Duplicate

$38150 \mu \mathrm{l}$ aliquots were removed and diluted 10,000 fold in $\mathrm{MB}$, using a 1000 -fold dilution of $50 \mu \mathrm{l}$

382 cell suspension into $50 \mathrm{~mL}$ followed by a 10-fold dilution of $5 \mathrm{~mL}$ aliquot of this dilution into 45

$383 \mathrm{~mL}$ medium in $50 \mathrm{~mL}$ Falcon tubes. For both strains, $10 \mu \mathrm{L}$ of the 10,000 -fold diluted material

384 was spread onto duplicate non-selective MB agar plates. The plate was incubated for 12-16 hours

385 at $37^{\circ} \mathrm{C}$ after which the number of colonies, typically $100-200$, was counted and used to calculate

386 the number of CFU in the original undiluted culture sample. These data were plotted at week

387 zero in Figure 3. The remainder of the $6 \mathrm{~mL}$ culture was split into separate Eppendorf tubes for

388 cryopreservation in glycerol as described in the Materials and Methods Section. A single

389 Eppendorf tube containing the glycerol stock was removed and thawed on ice each week for 11

390 weeks. CFU/ mL was measured as above, taking into account dilution due to glycerol addition. 
391 We also quantified the ability of $O$. indolifex and $R$. denitrificans cultures to be revived from

392 cryopreservation by measuring how much growth was achieved by glycerol stocks used as

393 inoculant each week over 11 weeks (Figure 3, square data points). Duplicate $50 \mu \mathrm{L}$ aliquots were

394 removed from an initial $6 \mathrm{~mL}$ culture and each used to inoculate $10 \mathrm{~mL} \mathrm{MB}$ which was then

395 incubated at $37^{\circ} \mathrm{C}$ for $12-16$ hours with shaking at $200 \mathrm{RPM}$ and the $\mathrm{OD}_{600}$ measured. These data

396 were plotted at week zero in Figure 3. $50 \mu \mathrm{L}$ aliquots were subsequently removed from a

397 glycerol stock each week and used to inoculate $10 \mathrm{~mL} \mathrm{MB}$ prior to incubation and $\mathrm{OD}_{600}$ 398 measurement as above.

399 In Figure 3 the survival of cells is plotted as $\mathrm{CFU} / \mathrm{mL}$ as a function of weeks spent at $-80^{\circ} \mathrm{C}$.

400 Both $R$. denitrificans (Figure 3A) and O. indolifex (Figure 3B) show a sharp initial decrease in

401 cell survival after one week in a glycerol stock solution at $-80^{\circ} \mathrm{C}$, compared to their starting 402 viability before glycerol addition (week zero). For both species, from weeks 1-11 there is a 403 shallow downward trend from $\approx 8 \times 10^{7} \mathrm{CFU} / \mathrm{mL}$ to $\approx 4 \times 10^{7} \mathrm{CFU} / \mathrm{mL}$. The ability of the cells to 404 be revived by growth in liquid culture is plotted in Figure 3 as $\mathrm{OD}_{600}$ after 12-16 hours growth as 405 a function of weeks at $-80^{\circ} \mathrm{C}$. Unlike survival performance, which decreases over time, revival 406 remains effectively constant throughout the 11 weeks for both species.

407 These data indicate that in our hands the Roseobacter strains remain viable over 11 weeks and 408 are likely to remain viable over much longer periods, particularly when considering revival by 409 growth in liquid culture. Interestingly, $R$. denitrificans and $O$. indolifex both grew well at $37^{\circ} \mathrm{C}$.

410 This observation confirmed reports by Bruhn et al. (2006) and Christie-Oleza et al. (2012) that

411 Roseobacter strains can be cultivated over a broad range of temperatures. By contrast, Lafay et

412 al. (1995) reported that incubation at $37^{\circ} \mathrm{C}$ failed to elicit growth of $R$. denitrificans. This suggest

413 Roseobacter strains may be sensitive to unidentified variations in handling and provenance to a 
414 degree that is not typically observed with biotechnology 'workhorse' organisms such as E. coli.

415 Preliminary data available here

416 http://2012.igem.org/Team:University_College_London/Research/MarineBacteria, show growth

417 of $O$. indolifex and $E$. coli at $37^{\circ} \mathrm{C}$ and $25^{\circ} \mathrm{C}$ in $10 \mathrm{~mL}$ culture volumes in $50 \mathrm{~mL}$ Falcon tubes. At

418 both temperatures, $O$. indolifex shows more growth in MB 2216 than LB and E. coli shows more

419 growth in LB than MB 2216.

\section{Chloramphenicol sensitivity of Roseobacter strains}

422 Chloramphenicol is used to select for retention of the widely used pSB3C5 BioBrick ${ }^{\mathrm{TM}}$ plasmid

423 backbone that encodes a chloramphenicol resistance gene as its selectable marker. In our view a 424 major step in establishing an organism as a tractable chassis for synthetic biologists use is to 425 demonstrate compatibility with standard tools that have been widely adopted by the synthetic 426 biologist community. To determine if $\mathrm{pSB} 3 \mathrm{C} 5$ BioBrick $^{\mathrm{TM}}$ could be maintained by the 427 Roseobacter strains in this study we sought first to establish the minimum chloramphenicol 428 concentration required to suppress cell growth, being mindful of the $30 \mu \mathrm{g} / \mathrm{mL}$ minimal 429 inhibitory chloramphenicol concentration reported by Piekarski et al. (2009). For E. coli and all 430 three Roseobacter strains, growing cultures were diluted and varying concentrations of 431 chloramphenicol added before growth was monitored by $\mathrm{OD}_{600}$ measurements.

432 Figure 3 shows measurements of cell growth over an eight hour period after chloramphenicol 433 addition. The data indicates that at least $17 \mu \mathrm{g} / \mathrm{mL}$ of chloramphenicol is required to suppress 434 growth of all Roseobacter strains, with lower concentrations permitting growth. Where a higher 435 chloramphenicol concentration is used, as in the case of $34 \mu \mathrm{g} / \mathrm{mL}$ chloramphenicol used for $R$. 436 denitrificans, no greater effect is observed in comparison to $17 \mu \mathrm{g} / \mathrm{mL}$ (Figure 3B). 
438 Attempted plasmid transformation of Roseobacter strain cells

439 We mapped a number of different parameters with respect to plasmid transformation of

440 Roseobacter strain cells in an attempt to establish a robust and straightforward protocol for

441 engineering these cells (Figure 4). Piekarski et al. (2009) methods were attempted alongside a

442 selection of alternative approaches. Figure 4 is a bubble chart that provides an overview of the

443 conditions for which we established transformation efficiency for E. coli, Roseobacter strains or

444 both. Although no transformation of Roseobacter strains was observed we suggest the selection

445 of conditions investigated can serve as a starting point for future efforts to identify a suitably

446 robust and effective protocol. Below we discuss the individual experimental conditions of note.

447 Electroporation using method A (see Materials and Methods) was used to attempt to transform

448 all E. coli and all Roseobacter strains with 50ng, 250ng, 500ng and 1000ng of pSB3C5 with

449 voltages of zero (as control) and $2.5 \mathrm{kV}$ (Figure 4). For D. shibae further voltages of $0.5 \mathrm{kV}, 1 \mathrm{kV}$,

$450 \quad 1.5 \mathrm{kV}$ and $3 \mathrm{kV}$ were used with $250 \mathrm{ng}$ and $1 \mu \mathrm{g}$ of pSB3C5 which features the p15 ori. Piekarski

451 et al. (2009) highlighted ori type as a potentially important factor for plasmid propagation in

452 Roseobacter species. As such electroporation Method B was used for transformation of $D$.

453 shibae with pSB3C5 and plasmids 2-5 as numbered in Table 1, which possess a range of

454 selectable markers and origins of replication (ori). 50ng of each plasmid was used with a voltage

455 of $2.5 \mathrm{kV}$ (Figure 4). Method $\mathrm{C}$ was also used for transformation of D. shibae at $2.5 \mathrm{kV}$ with

456 500ng each of plasmids 2-5 (Table 1).

457 Transformation was also attempted using heat shock with D. shibae and 100ng, 250ng and 500ng

458 of pSB3C5 (Figure 4). Control transformations (Figure 4, supplemental data) were performed

459 that omitted some or all of the following: antibiotic selection, plasmid or heat shock. All such 
460 control experiments yielded either colonies or clear plates along with expectations and indicated

461 that none of the methods or plasmids is inherently cytotoxic.

462 In addition to Piekarski et al. (2009), other groups have reported successful transformation of

463 Roseobacter genera such as Ruegeria mobilis (D'Alvise 2013) and Silicibacter (Miller and Belas

464 2006). These studies involved cell cultivation using Heart Infusion Broth and yeast extract, both

465 of which differ significantly from the marine growth media used for Roseobacter strains.

466

467 Cultivation of O. indolifex using the UCLHack12 incubator-shaker device

468 In our hands Roseobacter strains were in effect resistant to transformation. This led us to reflect

469 that development of such protocols may be addressed better in future with high throughput

470 automation approaches, using equipment such as the Tecan Genesis RMP device (Tecan,

471 Männedorf, Switzerland) which was recently kindly donated to LBHS by Paratopes Laboratories

472 (London, UK).

473 Although confident that simple and reliable protocols for Roseobacter transformation will be

474 identified in the near future using automated, high throughput experimentation, we were also

475 curious to investigate whether characteristic Roseobacter phenotypes, such as cold tolerance,

476 could be ported to E. coli. As a first step toward this goal a subgroup of the authors of this paper,

477 consisting only of LBHS members, designed a cloning strategy to isolate the antifreeze anf1

478 open reading frame from $O$. indolifex. To isolate this gene, $O$. indolifex was successfully

479 cultivated at LBHS using an open source device for growth of $O$. indolifex cells.

480 The device, designated the 'UCLHack12', was constructed using the components indicated in the

481 Materials and Methods section assembled in the configuration illustrated in Figure 5. A battery-

482 powered Arduino microcomputer was programmed to effect rotary movement of the electric 
483 motor. The electric motor was attached to a metal ring with an inserted pencil such that circular

484 motion of the motor caused the pencil to move back and forth. The pencil was firmly connected

485 to a cardboard panel that as a result was moved back and forth by the motion of the pencil

486 (Figure 5B, 5C). The cardboard panel attached to the pencil was also attached to a second, lower

487 cardboard panel by four metal springs to amplify lateral rocking motion. Adhesive tape was used

488 to secure agar plates (not shown), a $250 \mathrm{~mL}$ conical flask (Figure $5 \mathrm{~A}$ ) or $50 \mathrm{~mL}$ Falcon tubes

489 (Figure 5B) to the upper cardboard panel. Closing the lid of the container box provided sufficient

490 insulation to maintain an internal temperature of $28-30^{\circ} \mathrm{C}$. The UCLHack 12 device was designed

491 and constructed at LBHS solely through collaboration of undergraduate students and citizen

492 scientists.

493 At LBHS, $5 \mathrm{~mL}$ of $\mathrm{MB}$ in a $50 \mathrm{~mL}$ Falcon tube was inoculated using an $O$. indolifex glycerol 494 stock and incubated for 12-16 hours in the UCLHack12 device at $30^{\circ} \mathrm{C}$ with agitation of 495 approximately 100-150 RPM. Incubation in this manner achieved an observable increase in 496 medium turbidity, although regrettably optical density measurements were not taken during or 497 after incubation. One repeat of this procedure was performed before unknown LBHS users then 498 dismantled the UCLHack12 device without the knowledge of the authors.

500 Amplification and subcloning of the O. indolifex anf1 gene

$501400 \mu \mathrm{L}$ of the $O$. indolifex culture grown in the UCLHack12 device was conditioned using the

502 ethanol-based procedure to liberate genomic DNA and render it accessible to oligonucleotide

503 binding as part of preparative PCR. A subgroup of the authors of this study led by LBHS

504 members used web-based software tools to locate the anfl gene within the $O$. indolifex genome

505 (ENA - European Nucleotide Archive) and design primers to achieve both amplification of the 
506 anfl open reading frame (ORF) and subsequent sub-cloning into pSB1C3. via the restriction sites

507 required for compatibility with the BioBrick ${ }^{\mathrm{TM}}$ standard. The primers were delivered to UCL and

508 transported to LBHS for use in preparative PCR along with the $O$. indolifex genomic DNA

509 template material. At LBHS agarose gel electrophoresis revealed that a 285bp DNA fragment,

510 the expected size for the anfl gene, had been successfully amplified by PCR. A small mass of

511 linearised pSB1C3 backbone was also successfully amplified by PCR. A ligation reaction was

512 performed at LBHS to combine the anf1 gene fragment into pSB1C3 using standard molecular

513 biology techniques. If successful this reaction would yield a BioBrick ${ }^{\mathrm{TM}}$ plasmid encoding the

514 anfl open reading frame (ORF) as a BioBrick ${ }^{\mathrm{TM}}$ 'part' with the code BBa_K729016 according to

515 the notation of the Registry of Standard Biological Parts. The ligation reaction was transported to

516 UCL and used to transform competent E. coli W3110 strain cells. This step was necessary as the

517 LBHS was not at the time licensed to cultivate organisms harbouring modified genetic material.

518 Transformation at UCL using a standard heat shock method was successful: plasmid DNA was

519 isolated from transformants and positively identified as BBa_K729016 by restriction digest

520 (Figure 6). BBa_K729016 was subsequently the first BioBrick ${ }^{\mathrm{TM}}$ part submitted to the Registry

521 of Standard Biological Parts by a community laboratory led and run by members of the public.

522

523 Conclusions

524 Roseobacter cultivation and storage

525 Working as a team of students and 'DIY' biologists, we established that Roseobacter strains $O$.

526 indolifex and $R$. denitrificans are robust to glycerol-based cryopreservation at $-80^{\circ} \mathrm{C}$ over 11

527 weeks. We also successfully cultivated $O$. indolifex in the UCLHack12 incubator-shaker device

528 that we assembled entirely from publicly available components. Items such as the UCLHack12 
529 can help address issues of resource limitation that are common for newly founded community

530 laboratories. These achievements can now inform future efforts to establish Roseobacter strains

531 as synthetic biology chassis and also foster investigation of other strains that are relatively under-

532 explored due to their unknown or challenging genetic tractability.

533

534 Establishing recombinant DNA techniques in Roseobacter

535 We determined a minimum chloramphenicol concentration required to arrest growth of $O$.

536 indolifex and $R$. denitrificans to inform future protocols for plasmid propagation in these strains.

537 We also mapped the performance of a broad set of electroporation conditions using a battery of

538 plasmids with a range of replication origins and selectable markers, none of which yielded

539 transformants. We are confident that further work using equipment such as a Tecan Genesis

540 RMP device will establish Roseobacter strain transformation protocols that are both effective

541 and sufficiently robust to be usable by researchers in a diverse range of settings with respect to

542 available training and facilities.

544 De-skilling, bio-geoengineering and governance

545 Earth's biosphere has a profound impact on the planet's surface geology and meteorology

546 through processes such as the sulphur cycle (Alcolombri et al., 2015). In theory, synthetic

547 biology could be used to modify the biosphere via the re-writing of bacterial and eukaryotic

548 genomes. In practice, as genome editing and writing technologies are ported to a wider range of

549 chassis, many of which will be robust to marine or extreme environments, so the dilemmas and

550 choices raised by synthetic biology are set to increase. Bio-geoengineering and 'de-skilled'

551 molecular biology remain future possibilities rather than current realities. Despite this it is still 
552 tempting to envisage uncomfortable scenarios in which so-called hobbyists, benevolent or

553 otherwise, tinker with technologies, such as genome editing or the environmental release of

554 genetically modified organisms, whose dangers they do not fully understand (Jansen et al.,

555 2014). Part of our intention with this study was to present an example of responsible research

556 conduct in a community laboratory that was both safe and aspired to novelty and impact.

557 Upon submission of BBa_K729016 to the Registry of Biological Parts we took steps to raise 558 awareness of the first 'Public BioBrick ${ }^{\mathrm{TM}}$ ' through various media channels as part of the 559 activities of the 2012 UCL 'Plastic Republic' iGEM team. Events included an exhibition at the 560 Grant Museum, UCL, with the biological art practitioner, Dr Howard Boland (Boland 2013, 561 doctoral thesis). We also sought to capture the experiences of researchers involved in this work, 562 using techniques reported by Tweddle et al. (2012), to inform future projects. We invited LBHS 563 members to complete a written survey (Jordan et al., 2011) and video interviews to assess 564 whether participation in the project had impacted their research skills and outlook on 565 collaboration with academia. A preliminary record of these data can be found at the Wiki 566 homepage of the 2012 UCL

567 (http://2012.igem.org/Team:University_College_London/HumanPractice/DIYbio/Evaluation). A

568 clear outcome of the survey was that citizen scientists felt both their bench and study design 569 skills had increased. The need to work to deadlines was perceived as onerous. UCL students' 570 responses to the survey indicated they felt that community laboratories such as LBHS had 571 broadened their perception of the settings in which scientific research can take place within 572 society.

573 One obvious conclusion from this work is that genetic modification of Roseobacter cannot yet be 574 regarded as a de-skilled procedure (Tucker, 2012). However, this study also serves to illustrate 
575 that wider participation in science and engineering is now a reality (Figure 1). Familiar modes of

576 debate regarding science and technology separate industrial and academic researchers from

577 'members of the public'. This view is becoming obsolete as ever more powerful research tools,

578 such as cloud-based biological experimentation, genetic modification and high throughput

579 automation, become affordable and accessible to the 'general public'. Opportunity brings risk.

580 The possibility of unwanted outcomes caused by environmental release of designed organisms,

581 borne around the globe by winds and oceans, must of course be a central concern for all

582 researchers regardless of the setting in which their research is performed.

583

584 Acknowledgements

585 Dr Paola R. Gomez-Pereira (National Oceanography Centre, Southampton, United Kingdom) 586 and Miss Yeping Lu contributed to developing the concept of this study.

\section{References}

589 Alcolombri U, Ben-Dor S, Feldmesser E, Levin Y, Tawfik DS, Vardi A. 2015. Identification of

590 the algal dimethyl sulfide-releasing enzyme: A missing link in the marine sulfur cycle. Science $591348: 1466-1469$.

592

593 Alibu VP, Storm L, Haile S, Clayton C, Horn D. 2005. A doubly inducible system for RNA 594 interference and rapid RNAi plasmid construction in Trypanosoma brucei. Molecular and 595 Biochemical Parasitology 139:75-82.

596

Alper J. 2009. Biotech in the basement. Nature Biotechnology 27:1077-1078. 
600 Alibu VP, Storm L, Haile S, Clayton C, Horn D. 2005. A doubly inducible system for RNA

601 interference and rapid RNAi plasmid construction in Trypanosoma brucei. Mol Biochem

602 Parasitol. 139(1):75-82.

603

604

Bachmann BJ. 1972. Pedigrees of some mutant strains of Escherichia coli K-12. Bacteriological 605 Reviews 36:525-557.

606 607

Barnes DKA, Galgani F, Thompson RC, Barlaz M. 2009. Accumulation and fragmentation of 608 plastic debris in global environments. Philosophical Transactions of the Royal Society of London 609 B: Biological Sciences 364:1985-1998.

610

611

Belleflamme P, Lambert T, Schwienbacher, A. 2014. Crowdfunding: Tapping the right crowd.

612 Journal of Business Venturing 29:585-609

613

614 Boland H. (2013). Art from synthetic biology.

615 http://westminsterresearch.wmin.ac.uk/12742/1/Howard_BOLAND.pdf

616

617 Biebl H, Allgaier M, Tindall BJ, Koblizek M, Lünsdorf H, Pukall R, Wagner-Döbler I. 2005.

618 Dinoroseobacter shibae gen. nov., sp. nov., a new aerobic phototrophic bacterium isolated from

619 dinoflagellates. Int J Syst Evol Microbiol. 55(Pt 3):1089-96.

620

621

622 
623 Borg, Y. 2015. Design, Mathematical Modelling, Construction and Testing of Synthetic Gene

624 Network Oscillators to Establish Roseobacter Clade Bacteria and the Protozoan Trypanosoma 625 brucei as Synthetic Biology Chassis. PhD thesis. http://discovery.ucl.ac.uk/1472672/

626

627

628

629

630

631

632

633

634

635

636

637

638

639

640

641

642

643

644

645

646

647

648

649

650
Brinkhoff T, Giebel H-A, Simon M. 2008. Diversity, ecology, and genomics of the Roseobacter clade: a short overview. Archives of Microbiology 189:531-539.

Bruhn JB, Haagensen JAJ, Bagge-Ravn D, Gram L. 2006. Culture conditions of Roseobacter strain 27-4 affect its attachment and biofilm formation as quantified by real-time PCR. Applied and Environmental Microbiology 72:3011-3015.

Buchan A, González JM, Moran MA. 2005. Overview of the Marine Roseobacter Lineage. Applied and Environmental Microbiology 71:5665-5677.

Canton B, Labno A, Endy D. 2008. Refinement and standardization of synthetic biological parts and devices. Nature Biotechnology 26:787-793.

Chai Biotechnologies Inc. Chai. Available at www.chaibio.com (accessed 9 July 2012).

Christie-Oleza JA, Piña-Villalonga JM, Bosch R, Nogales B, Armengaud J. 2012. Comparative proteogenomics of twelve Roseobacter exoproteomes reveals different adaptive strategies among these marine bacteria. Molecular \& cellular proteomics: MCP 11:M111.013110.

D'Alvise P. 2013. Aquaculture application and ecophysiology of marine bacteria from the Roseobacter clade. DTU Food.

Dash HR, Mangwani N, Chakraborty J, Kumari S, Das S. 2013. Marine bacteria: potential candidates for enhanced bioremediation. Applied Microbiology and Biotechnology 97:561-571. 
651

652 De Schutter K, Lin Y-C, Tiels P, Van Hecke A, Glinka S, Weber-Lehmann J, Rouzé P, Van de

653 Peer Y, Callewaert N. 2009. Genome sequence of the recombinant protein production host Pichia

654 pastoris. Nature Biotechnology 27:561-566.

655

656

657

658

659

660

661

662

663

664

665

666

667

668

669

670

671

672

673

674

675

676

Eriksen M, Lebreton LCM, Carson HS, Thiel M, Moore CJ, Borerro JC, Galgani F, Ryan PG, Reisser J. 2014. Plastic Pollution in the World's Oceans: More than 5 Trillion Plastic Pieces Weighing over 250,000 Tons Afloat at Sea. PLoS ONE 9:e111913.

ENA. European Nucleotide Archive. Available at http://www.ebi.ac.uk/ena/data/view/EDQ05862 (accessed 2 July 2015).

Freitag A, Pfeffer MJ. 2013. Process, Not Product: Investigating Recommendations for Improving Citizen Science "Success.” PLoS ONE 8:e64079.

González JM, Kiene RP, Moran MA. 1999. Transformation of sulfur compounds by an abundant lineage of marine bacteria in the alpha-subclass of the class Proteobacteria. Applied and Environmental Microbiology 65:3810-3819.

Hahnke S, Brock NL, Zell C, Simon M, Dickschat JS, Brinkhoff T. 2013. Physiological diversity of Roseobacter clade bacteria co-occurring during a phytoplankton bloom in the North Sea. Systematic and Applied Microbiology 36:39-48.

Hale B, Dilling L. 2011. Geoengineering, Ocean Fertilization, and the Problem of Permissible Pollution. Science, Technology \& Human Values 36:190-212. 
677 Hidalgo-Ruz V, Thiel M. 2013. Distribution and abundance of small plastic debris on beaches in

678 the SE Pacific (Chile): A study supported by a citizen science project. Marine Environmental

679 Research 87-88:12-18.

680

681 Hochachka WM, Fink D, Hutchinson RA, Sheldon D, Wong W-K, Kelling S. 2012. Data-

682 intensive science applied to broad-scale citizen science. Trends in Ecology \& Evolution 27:130683137.

684

685

686

Intergovermental Marine Bioenergy with Carbon Sequestration (IMBECS) Protocol

http://climatecolab.org/web/guest/plans/-/plans/contestId/1300209/phaseId/1300656/planId/3710

687

688

689

690

691

692

IGEM 2015. Team Paris Bettencourt. Available

at http://2015.igem.org/Team:Paris_Bettencourt/Measurement (accessed 31 August 2015).

693

Jansen HJ, Breeveld FJ, Stijnis C, Grobusch MP. 2014. Biological warfare, bioterrorism, and biocrime. Clinical Microbiology and Infection: The Official Publication of the European Society 694 of Clinical Microbiology and Infectious Diseases 20:488-496.

695

696 Jin L, Walker AS, Fu G, Harvey-Samuel T, Dafa'alla T, Miles A, Marubbi T, Granville D,

697 Humphrey-Jones N, O’Connell S, Morrison NI, Alphey L. 2013. Engineered Female-Specific 698 Lethality for Control of Pest Lepidoptera. ACS Synthetic Biology 2:160-166.

699

700 Jordan RC, Gray SA, Howe DV, Brooks WR, Ehrenfeld JG. 2011. Knowledge gain and 701 behavioral change in citizen-science programs. Conservation Biology: The Journal of the Society 702 for Conservation Biology 25:1148-1154. 
704 Jorgensen ED, Grushkin D. 2011. Engage with, don't fear, community labs. Nature Medicine $705 \quad 17: 411-411$.

706

707

708

709

710

711

712

713

714

715

716

717

718

719

720

721

722

723

724

725

726

727

728

729

Kawrykow A, Roumanis G, Kam A, Kwak D, Leung C, Wu C, Zarour E, Sarmenta L, Blanchette M, Waldispühl J, Phylo players. 2012. Phylo: A Citizen Science Approach for Improving Multiple Sequence Alignment. PLoS ONE 7:e31362.

Lafay B, Ruimy R, de Traubenberg CR, Breittmayer V, Gauthier MJ, Christen R. 1995. Roseobacter algicola sp. nov., a new marine bacterium isolated from the phycosphere of the toxin-producing dinoflagellate Prorocentrum lima. International Journal of Systematic Bacteriology 45:290-296.

Ledford H. 2010. Garage biotech: Life hackers. Nature News 467:650-652.

Miller TR, Belas R. 2006. Motility is involved in Silicibacter sp. TM1040 interaction with dinoflagellates. Environmental Microbiology 8:1648-1659.

Müller KM, Arndt KM. 2012. Standardization in synthetic biology. Methods in Molecular Biology 813:23-43.

Pearce JM. 2012. Materials science. Building research equipment with free, open-source hardware. Science 337:1303-1304.

Petersen J, Frank O, Göker M, Pradella S. 2013. Extrachromosomal, extraordinary and essential-the plasmids of the Roseobacter clade. Applied Microbiology and Biotechnology 97:28052815. 
730 Piekarski T, Buchholz I, Drepper T, Schobert M, Wagner-Doebler I, Tielen P, Jahn D. 2009.

731 Genetic tools for the investigation of Roseobacter clade bacteria. BMC Microbiology 9:265.

732

733

734

735

736

737

738

739

740

741

742

743

744

745

746

747

748

749

750

751

752

753

754

755

756

Rayner S, Heyward C, Kruger T, Pidgeon N, Redgwell C, Savulescu J. 2013. The Oxford Principles. Climatic Change 121:499-512.

Ridgwell A, Singarayer JS, Hetherington AM, Valdes PJ. 2009. Tackling Regional Climate Change By Leaf Albedo Bio-geoengineering. Current Biology 19:146-150.

Sambrook J, Russell DW. 2001. Molecular Cloning: A Laboratory Manual. CSHL Press.

Santo M, Weitsman R, Sivan A. 2013. The role of the copper-binding enzyme - laccase - in the biodegradation of polyethylene by the actinomycete Rhodococcus ruber. International Biodeterioration \& Biodegradation 84:204-210.

Sepandj F, Ceri H, Gibb A, Read R, Olson M. 2004. Minimum inhibitory concentration (MIC) versus minimum biofilm eliminating concentration (MBEC) in evaluation of antibiotic sensitivity of gram-negative bacilli causing peritonitis. Peritoneal Dialysis International: Journal of the International Society for Peritoneal Dialysis 24:65-67.

Shetty R, Lizarazo M, Rettberg R, Knight TF. 2011. Assembly of BioBrick standard biological parts using three antibiotic assembly. Methods Enzymol. 498:311-26.

Shiba T. 1991. Roseobacter litoralis gen. nov., sp. nov., and Roseobacter denitrificans sp. nov., Aerobic Pink-Pigmented Bacteria which Contain Bacteriochlorophyll a. Systematic and Applied Microbiology 14:140-145. 
757 Shirk JL, Ballard HL, Wilderman CC, Phillips T, Wiggins A, Jordan R, McCallie E, Minarchek

758 M, Lewenstein BV, Krasny ME, Bonney R. 2012. Public Participation in Scientific Research: a

759 Framework for Deliberate Design. Ecology and Society 17.

760

761

Singarayer JS, Davies-Barnard T. 2012. Regional climate change mitigation with crops: context 762 and assessment. Philosophical Transactions of the Royal Society of London A: Mathematical,

763

764

765

766

767

768

769

770

771

772

773

774

775

776

777

778

779

780

781

782

783

Open PCR. Available at www.openpcr.org (accessed 10 July 2012).

Stilgoe J. 2015. Geoengineering as Collective Experimentation. Science and Engineering Ethics 1-19.

Tabor JJ. 2012. Modular gene-circuit design takes two steps forward. Nature Methods 9:10611063.

Tucker JB, Danzig R. 2012. Innovation, Dual Use, and Security: Managing the Risks of Emerging Biological and Chemical Technologies. Cambridge, Mass: MIT Press.

Tweddle JC, Robinson LD, Pocock MJO, Roy HE. 2012. Guide to citizen science: developing, implementing and evaluating citizen science to study biodiversity and the environment in the UK. Wallingford: NERC/Centre for Ecology \& Hydrology.

Wagner-Döbler I, Rheims H, Felske A, El-Ghezal A, Flade-Schröder D, Laatsch H, Lang S, Pukall R, Tindall BJ. 2004. Oceanibulbus indolifex gen. nov., sp. nov., a North Sea alphaproteobacterium that produces bioactive metabolites. International Journal of Systematic and Evolutionary Microbiology 54:1177-1184. 
784

785 Wagner-Döbler I, Biebl H. 2006. Environmental biology of the marine Roseobacter lineage.

786 Annual Review of Microbiology 60:255-280.

787

788 Wolyniak MJ, Alvarez CJ, Chandrasekaran V, Grana TM, Holgado A, Jones CJ, Morris RW, 789 Pereira AL, Stamm J, Washington TM, Yang Y. 2010. Building Better Scientists through Cross790 Disciplinary Collaboration in Synthetic Biology: A Report from the Genome Consortium for 791 Active Teaching Workshop 2010. CBE-Life Sciences Education 9:399-404.

792 793 794 795 796 797 798

799 800 801 802
Xu X, Nagarajan H, Lewis NE, Pan S, Cai Z, Liu X, Chen W, Xie M, Wang W, Hammond S, Andersen MR, Neff N, Passarelli B, Koh W, Fan HC, Wang J, Gui Y, Lee KH, Betenbaugh MJ, Quake SR, Famili I, Palsson BO, Wang J. 2011. The genomic sequence of the Chinese hamster ovary (CHO)-K1 cell line. Nature Biotechnology 29:735-741.

Zan J, Liu Y, Fuqua C, Hill RT. 2014. Acyl-homoserine lactone quorum sensing in the Roseobacter clade. International Journal of Molecular Sciences 15:654-669. 


\section{Figure Legends}

804 Figure 1. Project conception and organisation. Diagrammatic summary of the conception and

805 delivery of this study with respect to the roles of the people involved. Colours signify the 806 following- green: member of university faculty, purple: post-doctoral research assistant (PDRA), 807 blue: post-graduate (PG) research student, grey: undergraduate (UG) student and orange: 808 member of the public (MOP). Acronyms indicated the following authors- YB: Yanika Borg, AG: 809 Aurelija Marija Grigonyte, PB: Philipp Boeing, BW: Bethan Wolfenden, PS: Patrick Smith, WB:

810 William Beaufoy, SR: Simon Rose, TR: Tonderai Ratisai, AZ: Alexei Zaikin and DN: Darren N.

811 Nesbeth. Note that YB, SR, TR, WB and PS do not have a life science first degree. A) Typically,

812 a conventional study (right hand side of the panel) is performed by members of university faculty

813 as principal investigators (PIs), PDRAs, and PG research students, while UG students or MOPs

814 tend not to be involved in primary research roles. This study (left hand side of the panel) featured

815 no PDRAs, three UG students and four MOPs. B) A conventional study (right hand side of the 816 panel) is conceived and planned by PIs who bid for funds to support a given number of PDRAs 817 and PG research students to carry out the work. Resultant data is then written up by the research 818 tem in a manuscript that is submitted to specialist scientific journals. In this conventional model

819 MOPs will only learn of the research via general media such as national newspapers. This study 820 (left hand side of the panel) was conceived and planned solely by UGs students and MOPs. A PG 821 research student then assisted with experimentation and UCL faculty members assisted with 822 writing up the resultant data.

823

824 Figure 2. Robustness of Roseobacter to glycerol-based cryopreservation. Aliquots of $R$. 825 denitrificans (graph A) and O. indolifex (graph B) cells were stored in 17\% v/v glycerol solution 
826 at $-80^{\circ} \mathrm{C}$. At the indicated time points post-storage, aliquots were thawed, diluted and either

827 spread on MB agar plates or used to inoculate liquid MB medium. 24 hours later CFU counts

828 (diamonds) and $\mathrm{OD}_{600}$ values (squares) were plotted. Error bars indicate standard deviation over

829 two biological repeats.

830

831 Figure 3. Chloramphenicol sensitivity of Roseobacter and $\boldsymbol{E}$. coli. Growing cultures of $D$.

832 shibae (graph A), R. denitrificans (graph B), O. indolifex (graph C) and E. coli (graph D) were

833 cultured in the presence of no antibiotic (diamonds), or chloramphenicol at $3.4 \mu \mathrm{g} / \mathrm{mL}$ (circles),

$8347 \mu \mathrm{g} / \mathrm{mL}$ (triangles), $17 \mu \mathrm{g} / \mathrm{mL}$ (crosses) or $34 \mu \mathrm{g} / \mathrm{mL}$ (squares). $\mathrm{OD}_{600}$ was then measured at

835 the time-points indicated. Error bars indicate standard deviation over two biological repeats.

836

837 Figure 4. Plasmid transformation method performance map. Bubble chart in which

838 transformation results are plotted as crosses when no Roseobacter strain transformant colonies

839 are observed or closed grey circles when E. coli colonies are observed (circle size indicating

840 colony numbers, see key), as a function of plasmid mass (y axis) and kilovolts used (x axis, zero

841 for heat shock method). E. coli are only used where indicated by grey circles. Red numbering

842 indicates the plasmids, method and Roseobacter strains used in each experiment: 1) Method A

843 was used to attempt transformation of $D$. shibae, $R$. denitrificans and $O$. indolifex with pSB3C5

844 at the indicated voltage and zero volts as control. 2) Method A was again used in an attempt to

845 transform $D$. shibae with pSB3C5. 3) Method C was used to attempt transformation of D. shibae

846 with plasmids numbered 2-5 in Table 1, using the appropriately selective MB agar plates. 4)

847 Method B was used to attempt transformation of $D$. shibae with plasmids numbered 2-5 in Table

848 1. 5) The heat shock method was attempted for transformation of $D$. shibae with pSB3C5. 
850 Figure 5. The UCLHack12 open source incubator-shaker device. A) Photograph of the

851 device to which a $250 \mathrm{~mL}$ conical flask is attached with tape, in situ within the 42L Argos Cool

852 Box. B) Photograph showing the wooden blocks used as a supportive housing for the Maplin

853 Electronics electric motor, the electric cables and the spring-assisted shaker platform to which a

$85450 \mathrm{~mL}$ Falcon tube is attached with tape. C) Schematic diagram of the arrangement of 855 components used to construct the device. D) Photograph of the closed 42L Argos Cool Box 856 containing the functioning device.

857

858 Figure 6. Amplification and subcloning of anf1. Panel A is a schematic overview depicting the 859 primers (black triangles) used to PCR-amplify the anfl ORF to successfully yield an amplicon 860 fragment encoding EcoRI and XbaI sites upstream and SpeI and PstI sites downstream of the 861 anf1 ORF. The fragment was then subcloned into pSB3C1 to form the BioBrick ${ }^{\mathrm{TM}}$ plasmid, 862 BBa_K729016. Panel B consists of photographs of agarose gel lanes in which uncut 863 BBa_K729016 (lane U), BBa_K729016 digested with EcoRI and PstI enzymes (lane C) and 864 DNA ladder (lane L) have been run. The 400bp and 2000bp bands of the ladder are indicated by 865 grey and black triangles respectively. 


\section{Figure 1 (on next page)}

Project conception and organisation.

Diagrammatic summary of the conception and delivery of this study with respect to the roles of the people involved. Colours signify the following- green: member of university faculty, purple: post-doctoral research assistant (PDRA), blue: post-graduate (PG) research student, grey: undergraduate (UG) student and orange: member of the public (MOP). Acronyms indicated the following authors- YB: Yanika Borg, AG: Aurelija Marija Grigonyte, PB: Philipp Boeing, BW: Bethan Wolfenden, PS: Patrick Smith, WB: William Beaufoy, SR: Simon Rose, TR: Tonderai Ratisai, AZ: Alexei Zaikin and DN: Darren N. Nesbeth. Note that YB, SR, TR, WB and PS do not have a life science first degree. A) Typically, a conventional study (right hand side of the panel) is performed by members of university faculty as principal investigators (PIs), PDRAs, and PG research students, while UG students or MOPs tend not to be involved in primary research roles. This study (left hand side of the panel) featured no PDRAs, three UG students and four MOPs. B) A conventional study (right hand side of the panel) is conceived and planned by Pls who bid for funds to support a given number of PDRAs and PG research students to carry out the work. Resultant data is then written up by the research tem in a manuscript that is submitted to specialist scientific journals. In this conventional model MOPs will only learn of the research via general media such as national newspapers. This study (left hand side of the panel) was conceived and planned solely by UGs students and MOPs. A PG research student then assisted with experimentation and UCL faculty members assisted with writing up the resultant data. 


$\frac{\text { This study }}{\text { DN AZ }}$

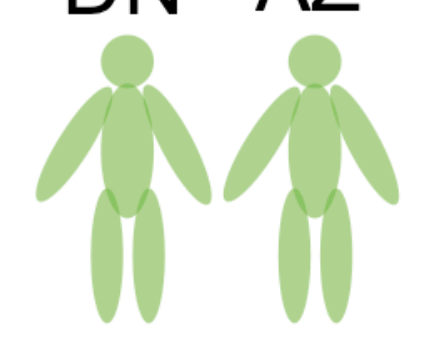

Fac.

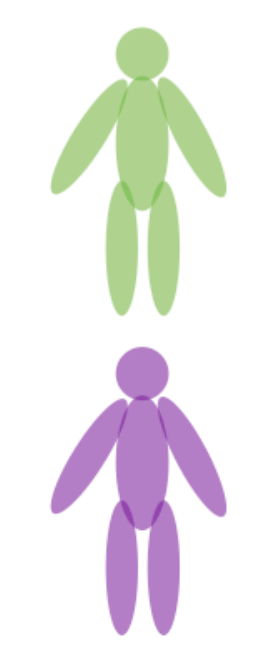

YB

PDRA

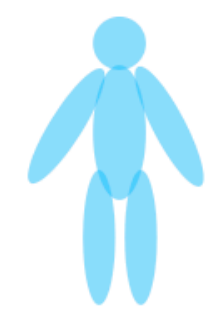

PG student

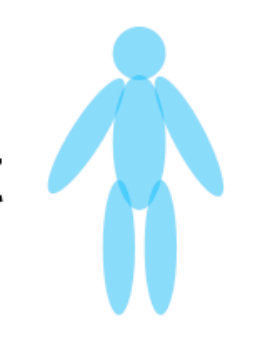

BW PB AG

UG student

General

Media

Specialist Publications

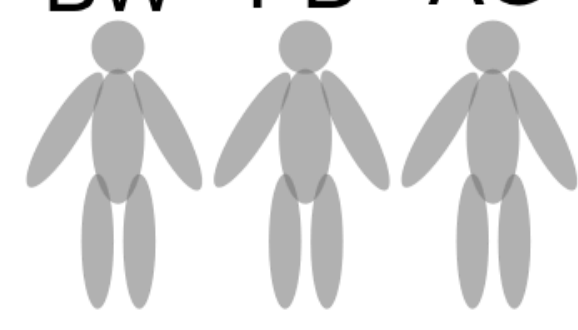

TR SR WB PS

MOP 
Figure 2 (on next page)

Robustness of Roseobacter[i] to glycerol-based cryopreservation.

Aliquots of R. denitrificans (graph A) and O. indolifex (graph B) cells were stored in 17\% v/v glycerol solution at $-80^{\circ} \mathrm{C}$. At the indicated time points post-storage, aliquots were thawed, diluted and either spread on MB agar plates or used to inoculate liquid MB medium. 24 hours later CFU counts (diamonds) and $\mathrm{OD}_{600}$ values (squares) were plotted. Error bars indicate standard deviation over two biological repeats. 


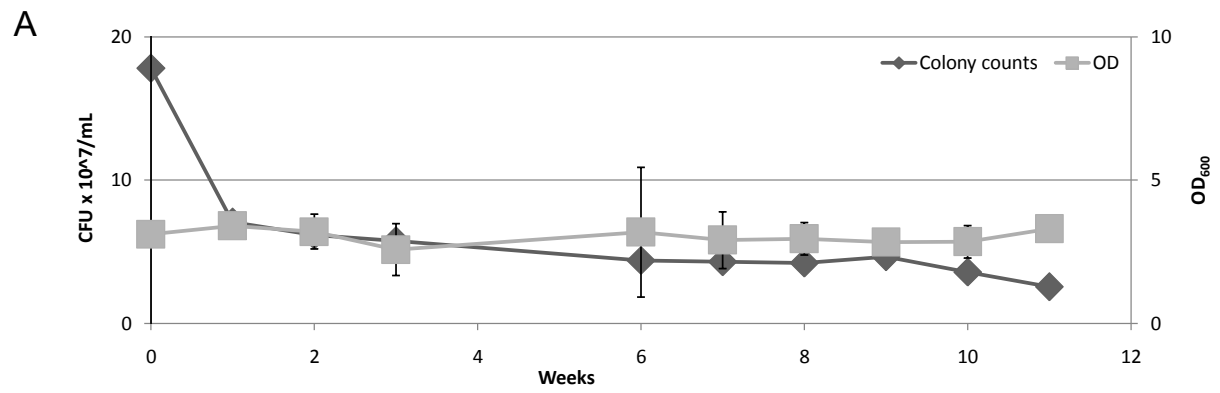

B

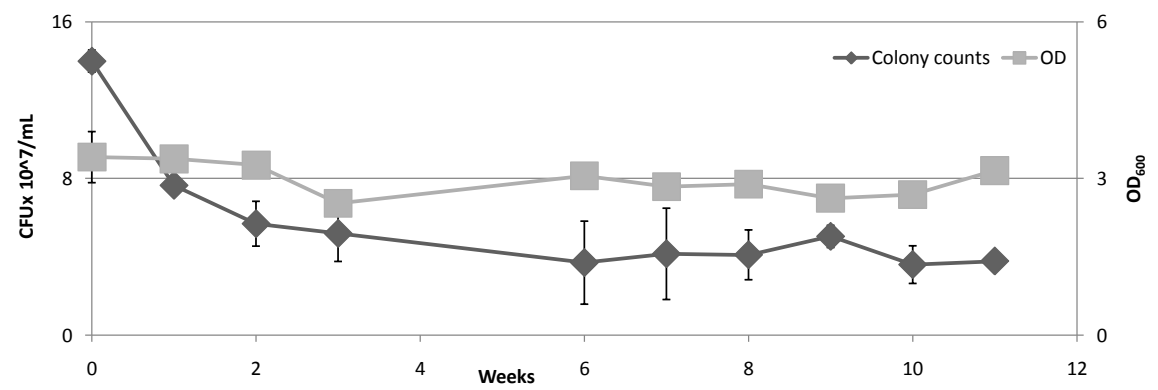


Figure 3 (on next page)

Chloramphenicol sensitivity of Roseobacter and E. coli.

Growing cultures of D. shibae (graph A), R. denitrificans (graph B), O. indolifex (graph C) and E. coli (graph D) were cultured in the presence of no antibiotic (diamonds), or chloramphenicol at $3.4 \mu \mathrm{g} / \mathrm{mL}$ (circles), $7 \mu \mathrm{g} / \mathrm{mL}$ (triangles), $17 \mu \mathrm{g} / \mathrm{mL}$ (crosses) or $34 \mu \mathrm{g} /$ $\mathrm{mL}$ (squares). $\mathrm{OD}_{600}$ was then measured at the time-points indicated. Error bars indicate standard deviation over two biological repeats. 


\section{Figure 4 (on next page)}

\section{Plasmid transformation method performance map.}

Bubble chart in which transformation results are plotted as crosses when no Roseobacter strain transformant colonies are observed or closed grey circles when E. coli colonies are observed (circle size indicating colony numbers, see key), as a function of plasmid mass ( $y$ axis) and kilovolts used ( $x$ axis, zero for heat shock method). E. coli are only used where indicated by grey circles. Red numbering indicates the plasmids, method and Roseobacter strains used in each experiment: 1) Method A was used to attempt transformation of $D$. shibae, $R$. denitrificans and $O$. indolifex with $\mathrm{pSB} 3 \mathrm{C} 5$ at the indicated voltage and zero volts as control. 2) Method $A$ was again used in an attempt to transform D. shibae with pSB3C5. 3) Method $C$ was used to attempt transformation of $D$. shibae with plasmids numbered 2-5 in Table 1 , using the appropriately selective MB agar plates. 4) Method B was used to attempt transformation of $D$. shibae with plasmids numbered 2-5 in Table 1. 5) The heat shock method was attempted for transformation of $D$. shibae[i] with pSB3C5. 


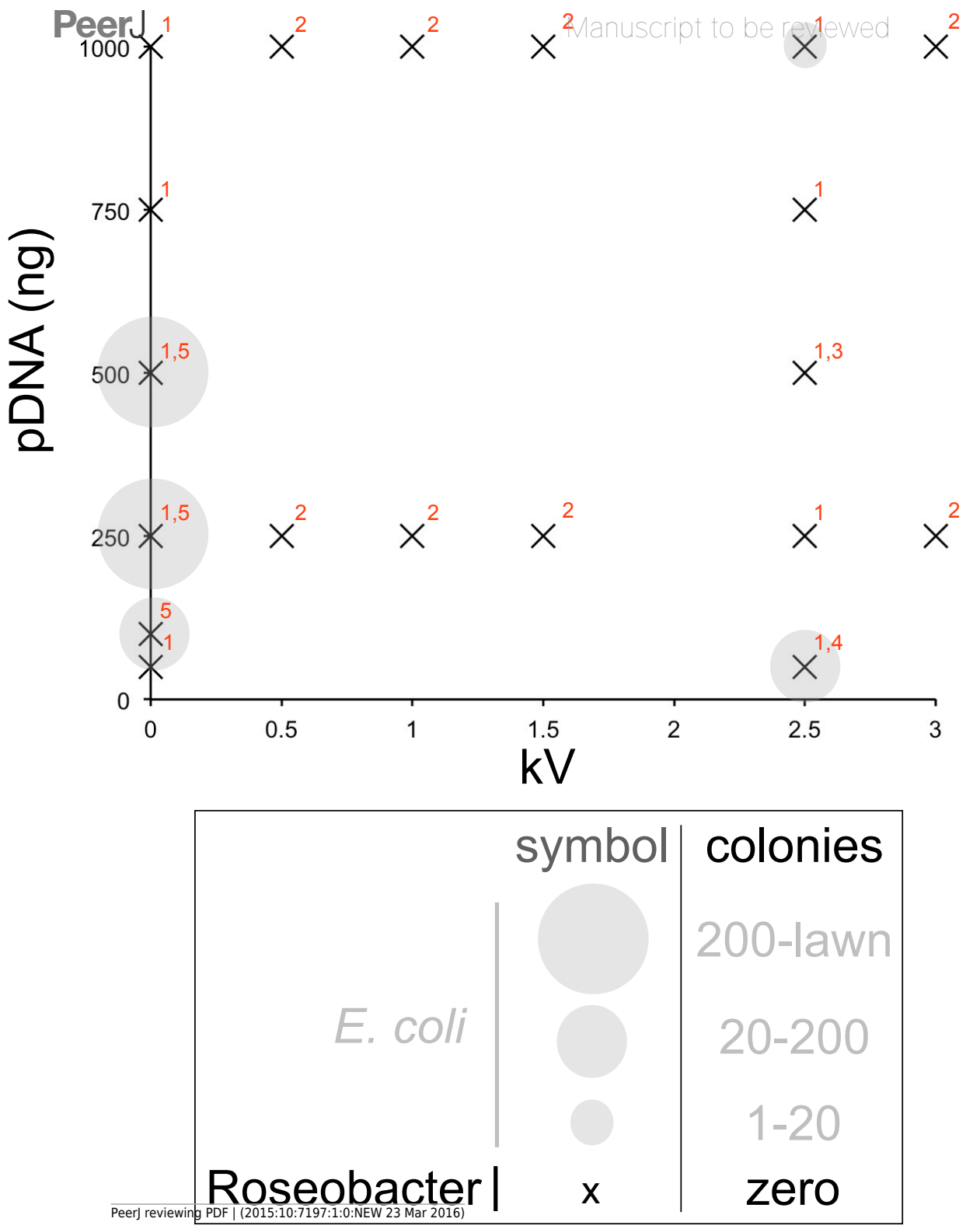


Figure $\mathbf{5}$ (on next page)

The UCLHack12 open source incubator-shaker device.

A) Photograph of the device to which a $250 \mathrm{~mL}$ conical flask is attached with tape, in situ within the $42 \mathrm{~L}$ Argos Cool Box. B) Photograph showing the wooden blocks used as a supportive housing for the Maplin Electronics electric motor, the electric cables and the spring-assisted shaker platform to which a $50 \mathrm{~mL}$ Falcon tube is attached with tape. C) Schematic diagram of the arrangement of components used to construct the device. D) Photograph of the closed 42L Argos Cool Box containing the functioning device. 


\section{PeerJ}

A)
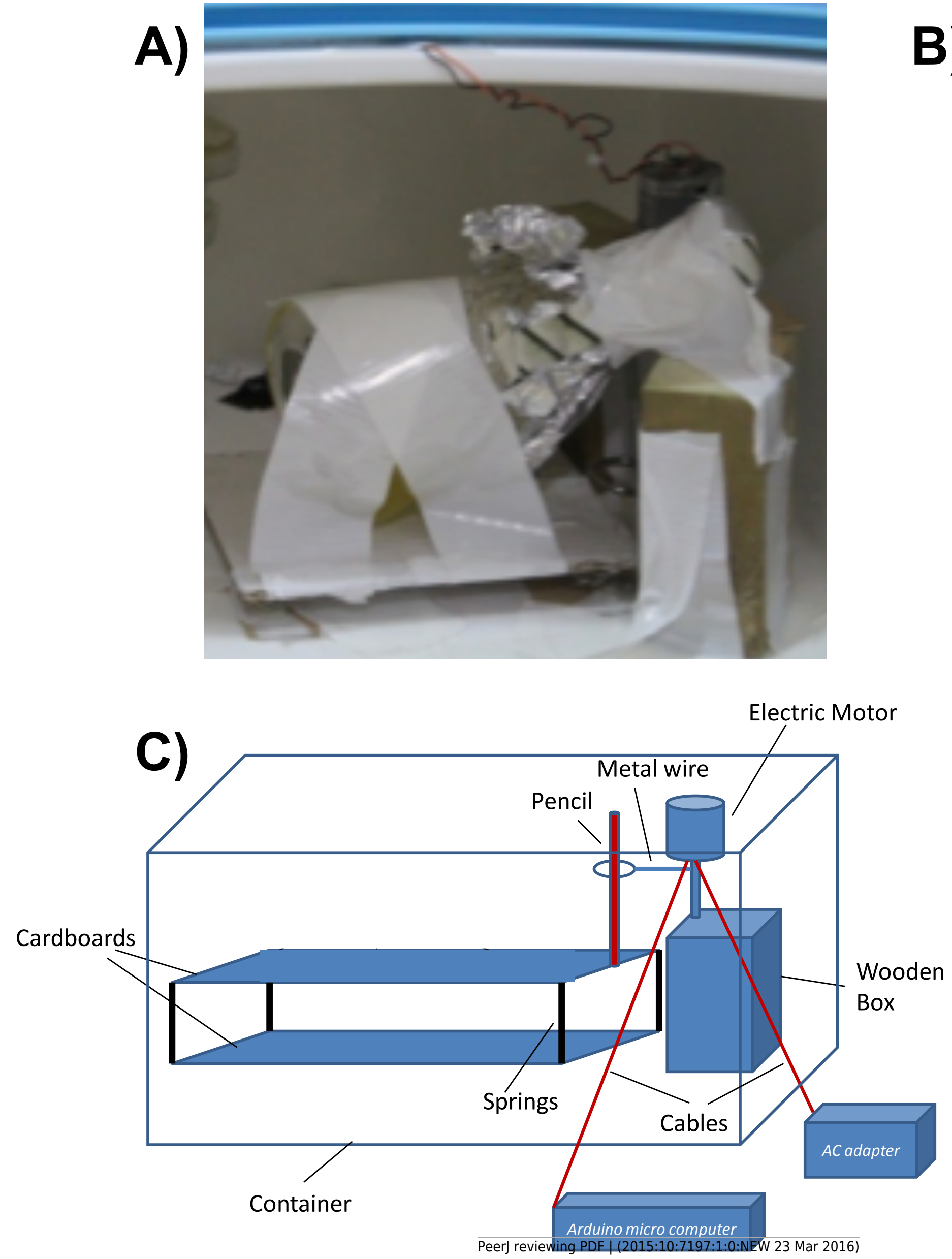

Manuscript to be reviewed
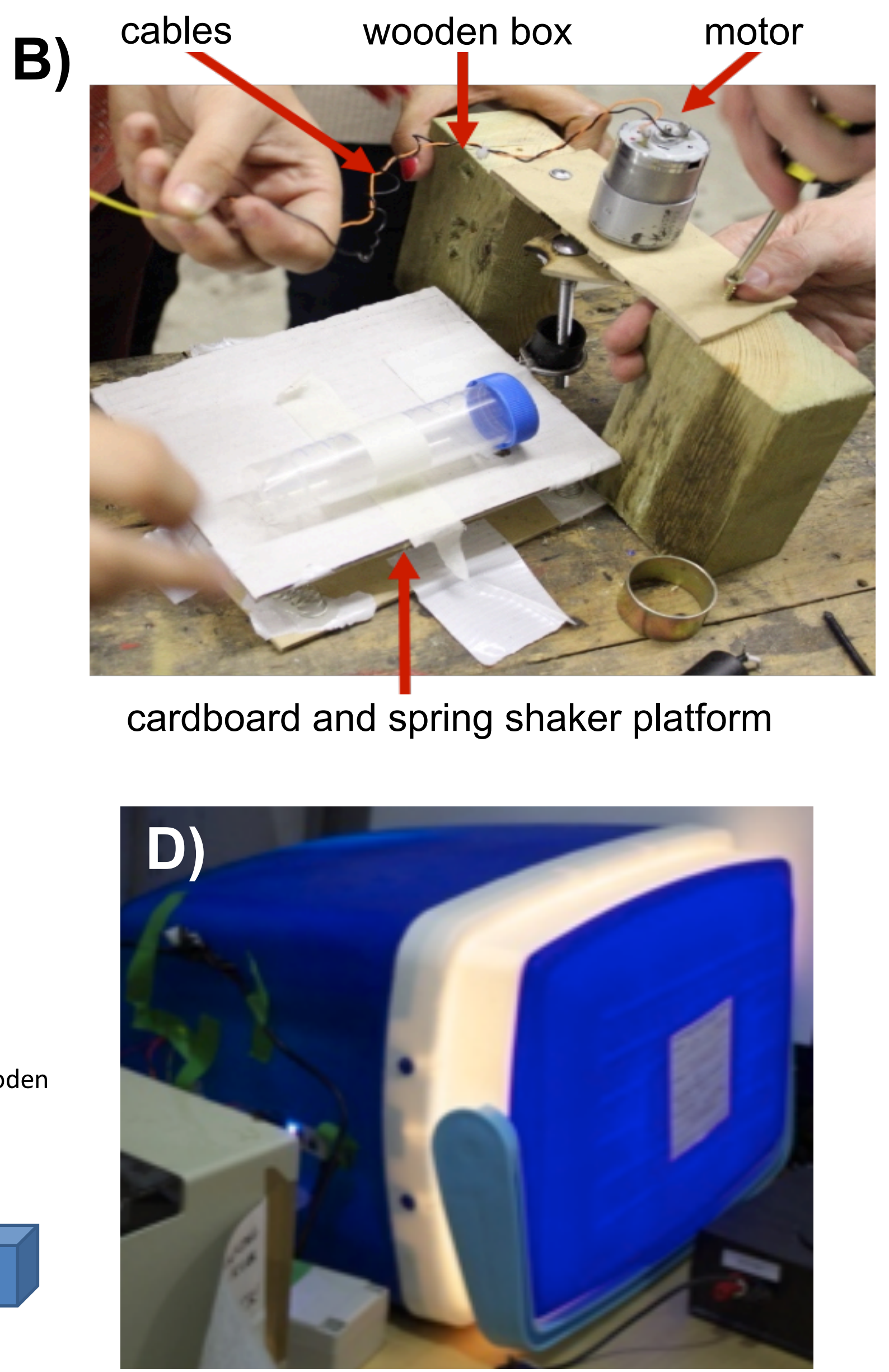


\section{Figure 6 (on next page)}

Amplification and subcloning of anf1[i].

Panel A is a schematic overview depicting the primers (black triangles) used to PCR-amplify the anf1 ORF to successfully yield an amplicon fragment encoding EcoRI and Xbal sites upstream and Spel and Pstl sites downstream of the anf1 ORF. The fragment was then subcloned into PSB3C1 to form the BioBrick ${ }^{\mathrm{TM}}$ plasmid, BBa_K729016. Panel B consists of photographs of agarose gel lanes in which uncut BBa_K729016 (lane U), BBa_K729016 digested with EcoRI and Pstl enzymes (lane C) and DNA ladder (lane L) have been run. The $400 \mathrm{bp}$ and 2000bp bands of the ladder are indicated by grey and black triangles respectively. 
A)

B)
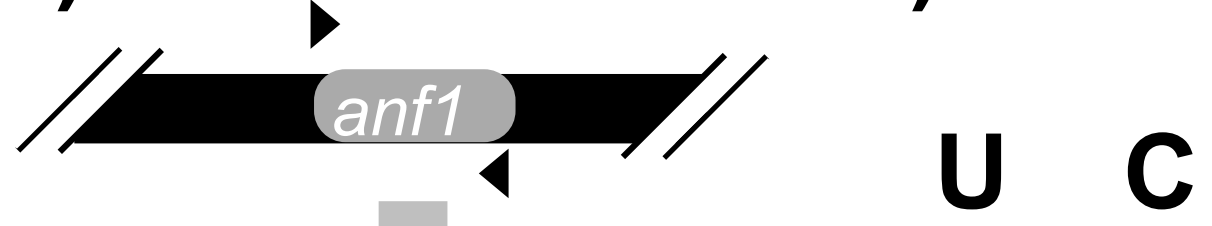

EX)anf1 (S)P

$285 b p$
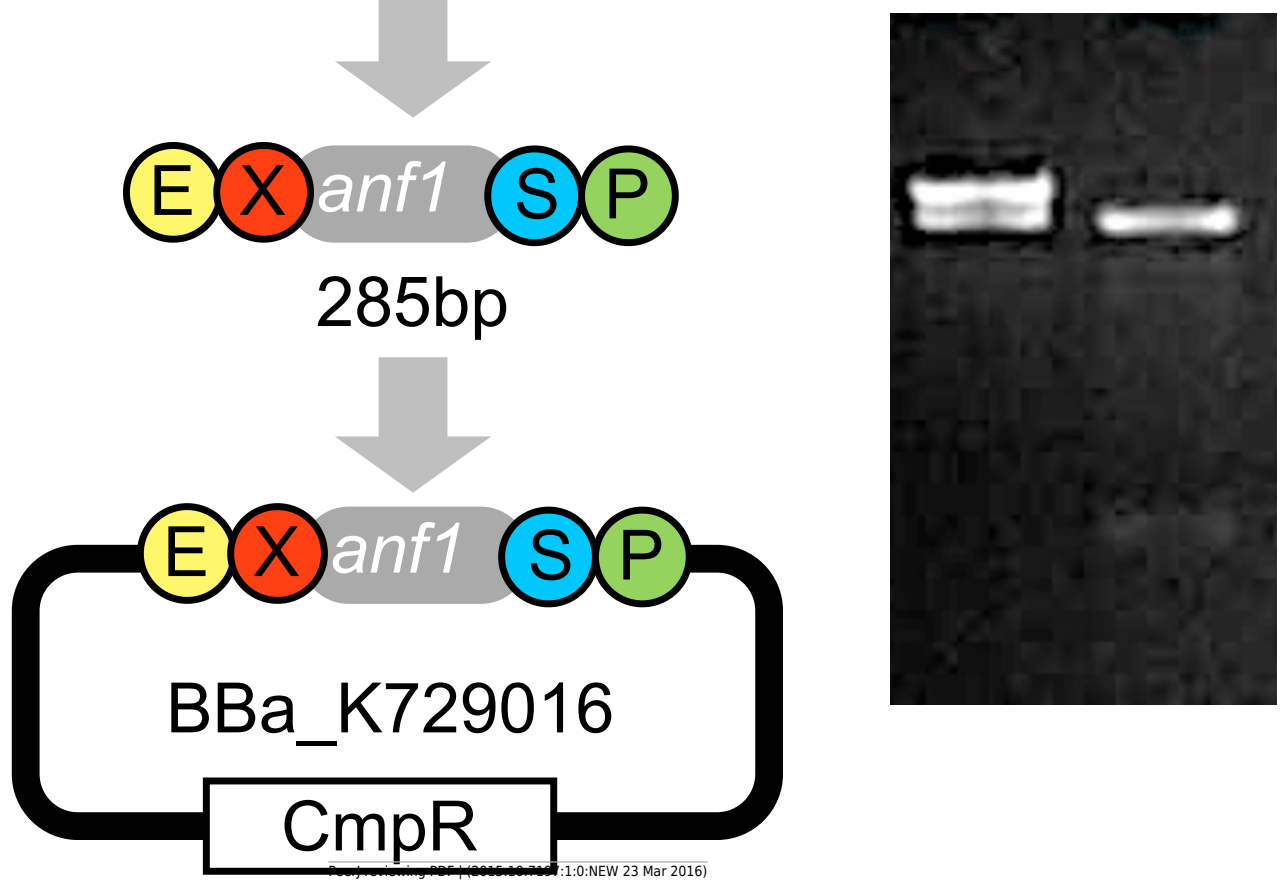


\section{Table $\mathbf{1}$ (on next page)}

Plasmids used in transformation study.

All plasmids were sourced directly from people or organisation listed except pHD1313, which was a king gift from Prof. Christine Clayton (Universität Heidelberg). 
1

\begin{tabular}{|l|l|l|l|l|}
\hline & Name & Ori & Selection & Source / Reference \\
\hline 1 & pSB3C5 & p15A & Chloramphenicol & BioBrick $^{\mathrm{TM}}$ Registry \\
\hline 2 & pA0815 & pBR322 & Ampicillin & Thermo Fisher Cat. No. V18020 \\
\hline 3 & pHD1313 & pUC & Ampicillin & Alibu et al. (2005) \\
\hline 4 & pRPGFPSIR2rp3 & pUC & Ampicillin & Borg (2015) \\
\hline 5 & pUBeK & pUC & Ampicillin & Borg (2015 \\
\hline
\end{tabular}

2

3 Table 1. Plasmids used in transformation study. All plasmids were sourced directly from 4 people or organisation listed except pHD1313, which was a king gift from Prof. Christine 5 Clayton (Universität Heidelberg). 6 